\title{
INTEGRATION ISSUES FOR USING INNOVATIVE DAYLIGHTING STRATEGIES IN LIGHT WELLS
}

\author{
M. Gholipour Gashniani a , Fatemeh Mehdizadeh Saradj a*, M. Faizi ${ }^{\text {a }}$ \\ ${ }^{a}$ Iran University of Science and Technology (IUST), Faculty of Architecture and Environmental Design, Tehran, Iran \\ e-mails: m.gholipour@umz.ac.ir,mfaizi@iust.ac.ir,mehdizadeh@iust.ac.ir*
}

Received: 14.08.2017 / Accepted: 20.09.2017 / Revised: 30.10.2017 / Available online: 15.12.2017

DOI: 10.1515/jaes-2017-0010

Keywords: Innovative daylighting system, Building, Architecture, light well, Integration

\begin{abstract}
:
"Light well" as one of the most common means of daylight tolls in building, experiences severe limitations and deserve special attention. The question is which strategy is the best for increasing the daylight penetration to the depth of buildings. One of the main challenges in deep plan is to guide daylight into the building core and this can be performed through daylighting strategies, but the choice of the proper innovative daylighting system (IDS) with several parameters is the problem. This paper aims to find elements for optimal choice and selecting context-compatible tools for light well. The result shows that four macro factors were found at the interaction of building and IDS. Identifying the integration components can play an effective role in decision-making or design a new tolls consistent with the physical conditions of light well and building to overcome the daylight crisis.
\end{abstract}

\section{INTRODUCTION}

Nowadays, dense cities have led towards the decrease of daylight penetration into the interior space. Daylight crisis in buildings brings significant challenges to architecture, in three domains of economic, health - wellbeing and environment. Given that currently $90 \%$ of our activities are indoor hence the quality and quantity of light is important (Altomonte, 2008). One of the common ways to increase the penetration of light into the building is possible through the atrium or a "light well" (Billinton and Karki, 2003). Researchers believe that the light wells potential are far from they are (Freewan, et al, 2014). Studies have shown that light wells in terms of providing appropriate brightness, only is efficient in 2 upper floors of buildings in providing required lighting (300lux) in $93 \%$ of daily hours during the year (Faizi, et al, 2016). In more depth light wells, the performance has sharply declined and at a depth of 8 floors it will be with $71 \%$ drop (Advanced building ltd, 2010).So the necessity of solving the crisis in highest light well is very important.

Current review paper has been developed based on four steps in order to improve the performance of light well as one of the conventional means of daylight penetration in deep plan buildings (Figure 1). In the first step, improvement approaches of light well performance were evaluated and classified based on how they are applying the changes.

\section{LIGHT WELL IMPROVEMENT APPROACHES}

The classification of studies about light wells improvement approach in terms of the modification method fall into the groups of "design", "modifications" and "utilization of IDS". In general, all of the three methods can be used, but it does not apply to dense contexts. Previous researches shows that more effort took in first and second phase, but the improvement is limited and requires high "well-index" that cannot be achieved in the conventional urban context (Faizi, et al, 2016). The findings demonstrate that the third phase (utilization of IDS) in theory has high potential but it needs more researches (Kim and Kim, 2010).

\section{INNOVATIVE DAYLIGHTING SYSTEMS (IDS)}

Given the potential of IDS, it is required to explore the challenges in selecting appropriate and context-compatible tools for light well. Reviewing the researches on IDS depicted four categories. The first category is focused on the innovative estimation methods (Mayhoub, 2011). The second category is focused on the performance improvement. The third group is based on decision making for selecting the suitable system (Naves, 2006). The fourth group, on which limited research has been conducted, aims to adapt systems to specific physical conditions of buildings (Hansen, 2006). Review indicates that context-orientation is one of the most important attributes of systems. Hence, a quantitative estimation of systems performance does not necessarily prove their success (Kim and Kim, 2010).

\footnotetext{
* Corresponding author. Fatemeh Mehdizadeh SARADJ, mehdizadeh@iust.ac.ir
} 


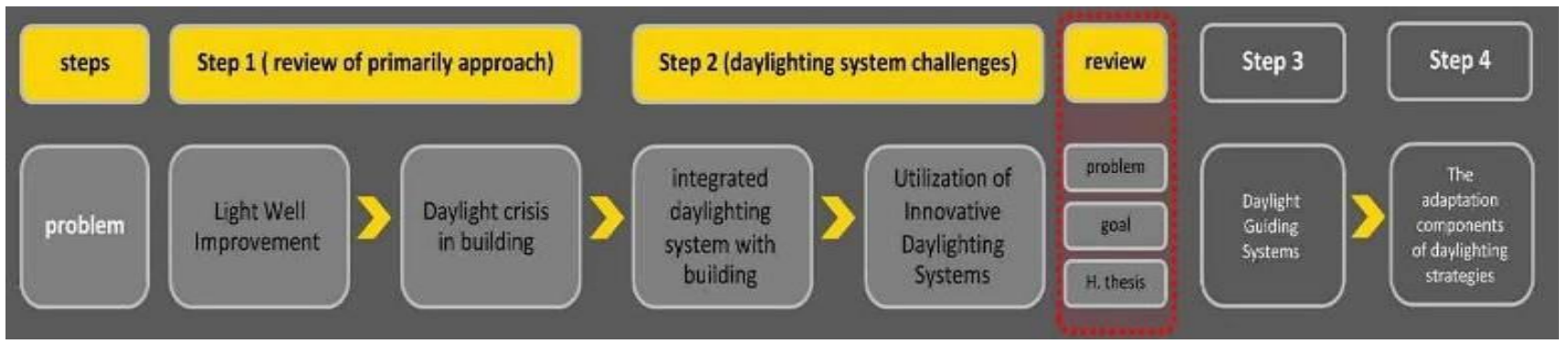

Figure 1. Linear diagram of the present research structure and its four steps

The investigations carried out in this step showed that parameters other than quantitative estimation are involved in the building-IDS interaction (Faizi, et al, 2016).

These parameters influence on the selection of suitable systems, and any lack of concern for internal and external criteria can result in incompliance of the system with the building (Figure 2). According to the importance of integrated design for architects, a deep analysis of daylighting technologies and their components can indicate the influencing factors for the selection of a suitable system for buildings (Delnoij, et al, 2003).

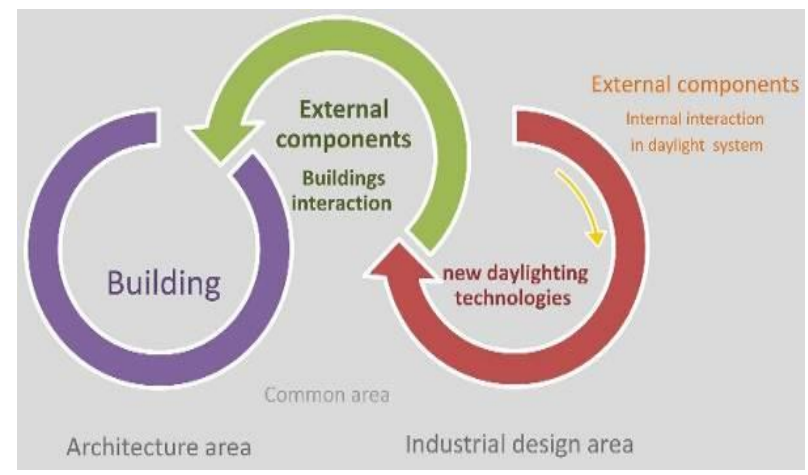

Figure 2. IDS integration in building

\section{DAYLIGHT GUIDING SYSTEMS}

Considering the great diversity of daylight guiding systems, the comprehensive classification will be needed. They can be classified by components performance. They consist of three important components: collector, transporter, and emitter (Ayers and Carter, 1995). Each of themes is of various types, which have been combined to produce different systems (Figure 3).

\subsection{Collectors}

Collectors are designed to receive light and prepare it for transport. Collectors can be classified into two groups of concentrating and redirecting (Faizi, et al, 2017).

\section{1) Concentrating Collectors:}

Concentrating collectors collect the light at different solar altitudes and azimuth angles, concentrate it, and then transport it to the light carrier. Several researches suggest that as the

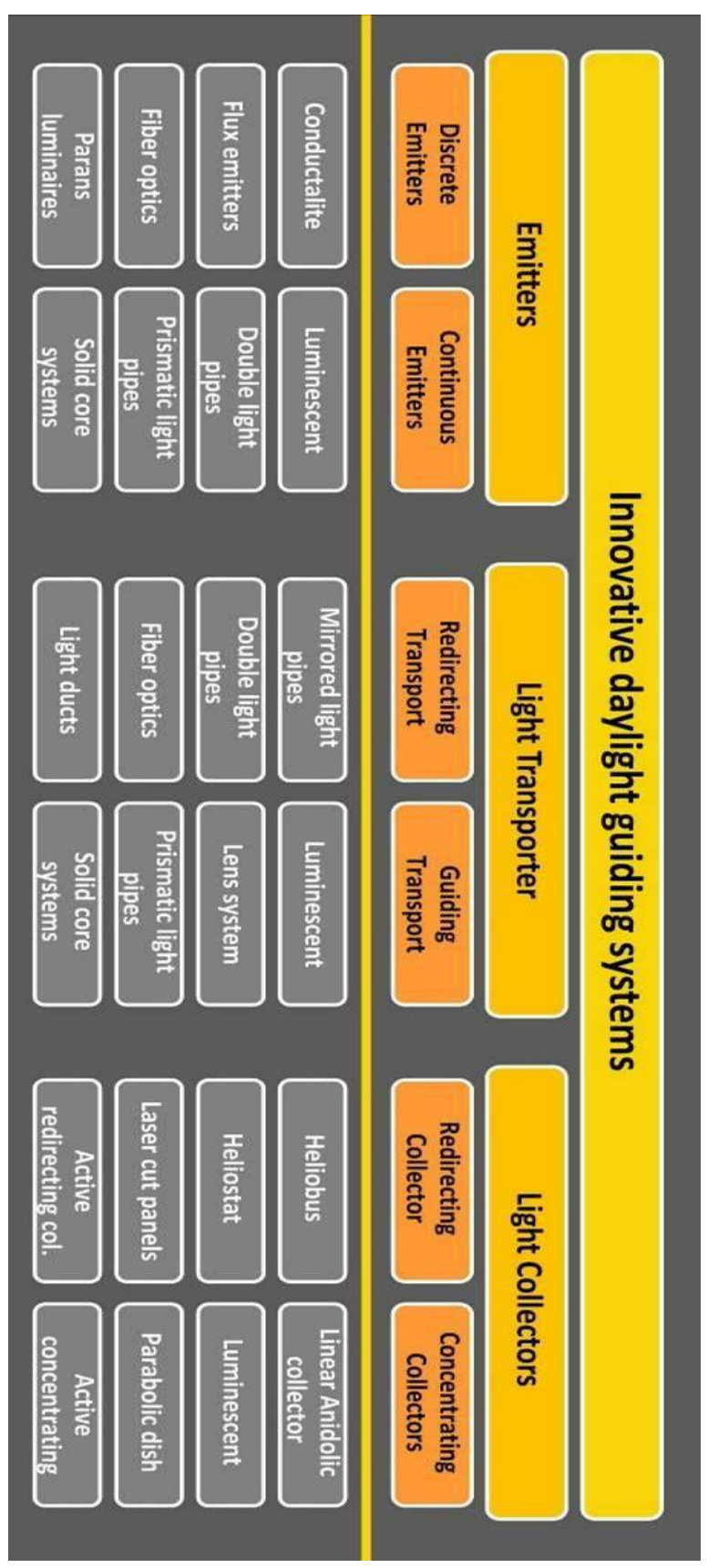

Figure 3. Extraction of innovation daylight guiding systems by performance of components 
light concentration level increases the cost of construction and the level of the technology increase drastically (Rosemann, et al, 2008). According to research results, the optimum light density is the 10 -degree density.

"Linear anidolic collector" can work in cloudy weather conditions due to its geometrical structure and is capable of collecting light from the upper center of the sky dome. One of the major problems is its physical integration problem with building form and city scape (Altherr and Gay, 2002). The flexibility of this system in the spaces is extremely low. "Anidolic zenithal openings" function by collecting diffuse light from a large part of the sky but do not allow sunlight to pass directly. One of the problems of this system is the increase in HVAC load under the influence of infrared and glare in interior spaces (Courret, et al, 1996). The "luminescent solar concentrator" is capable of concentrating the sunlight and diffusing it.

In this process, the natural colour will be change. One of the most important advantages of this system is the collection of light regardless of the solar altitude angle (Smestad, et al, 1990). "One of the limitations of this system is its low efficiency as only $10 \%$ of the collected light transforms into output light" (Earp, et al, 2004).

The "parabolic collector" works with active parabolic dishes, Fresnel lenses and parabolic concentrators. Given the light concentration, transport channels with smaller diameters and relatively high production costs are used, which require complicated technologies. Because of light concentration and its density, the possibility of fire hazard increases.

The active concentrating collector concentrates light using reflections of moving geometrical surfaces and allows absorption of more light in different directions. The systems such "solar canopy", "Parans system", and "Himawari system" use these collectors. The solar canopy is capable of collecting light at different solar altitudes and azimuth angles and allows light concentration. It consists of an array of flat moving mirrors that receive light at all angles and redirect it to secondary parabolic surfaces. This system is highly efficient in cloudy and sunny weather conditions. Moreover, the size and cube shape of this system facilitates physical compatibility and integration with the building.

In the Japanese "Himawari system", light is collected by multiple Fresnel lenses and it can be transported to a distance of $200 \mathrm{~m}$ with optic fibers. The quantity of the light diffused by the system under the sunny sky is 98000 lux (www.himawari-net.co, 2013).

In the Swedish "Parans system" the quantity of transported light in the sunny sky is 130000 lux and is estimated to be $4600 \mathrm{~lm}$ at a $10-\mathrm{m}$ distance from the collector (Figure 4)

(www.parans.com, 2013).

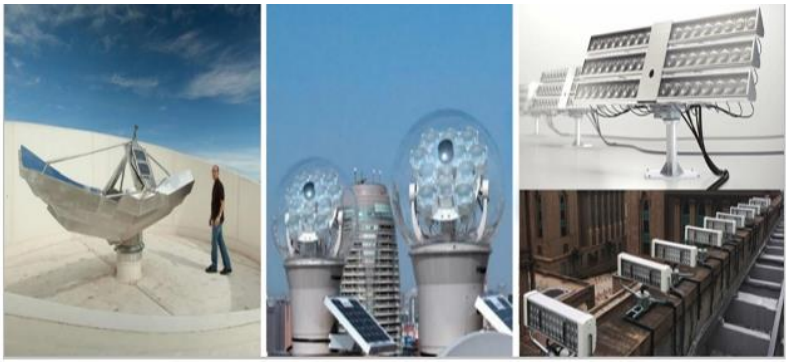

Figure 4. Parans, Himawari, Sundolier (www.Sundolier.com, 2013)

The American "Sundolier system" is in the category of motion concentrators and uses the parabolic dishes. This is capable of transporting $10000 \mathrm{~lm}$ in sunny conditions

(www.Sundolier.com, 2013).

\section{2) Light Redirecting Collector:}

The "Heliobus" with concave mirror collector transports the collected light to a prismatic pipe and redirects it to the emitters (Aizenberg, et al, 1996). Performance of This collector in equinox to the winter revolution is decreased. The maximum efficiency of the system is at noon. One of the problems of the Heliobus collector is its inability to collect light from the entire sky dome. The large size of system causes problems in combining this system with building (Hansen, 2006). The "Heliostat" is a light transport tool that transports light using reflective mirrors to the space. It improves the lighting of semi underground spaces by 11 times (with flat mirrors) and 15 times (with concave mirrors). Since this device is an active system, its high initial and maintenance cost is one of its disadvantages (Rosemann and Kaase, 2005). It requires a very high absorption surface, which affects the buildings form and cityscape and thus it requires the integrated design.

"Laser cut panels" are designed to allow maximum transmission of light at low altitude angles and minimum transfer of light at high altitude angles.

Active redirecting collectors are designed to increase light collection given the limitation on collector panel's size in buildings. One of these technologies is the "SunCentral" that uses the linear redirection technology known as "SunBeamer". SunBeamer collectors receive light from different directions at different solar altitudes. The Canadian SunCentral system allows for controlled collection of light with an array of motion linear mirrors. Since no high light concentration occurs in the collection phase, advanced technologies are not required in the diffusion phase. SunBeamer systems can be attached to luminescent redirecting pipes and linear redirecting systems. It can also reach a depth of $15 \mathrm{~m}$ in the space. SunBeamer systems can be utilized separately and are capable of transmitting light vertically without depth limitations. The modular and geometrical flexibility of this system allows the use of different arrangements and physical compatibility. Since this system uses direct sunlight, its efficiency is affected by different conditions. In cloudy weather conditions this system is less effective than concentrating systems and in sunny weather it supplies at least 350lux to interior spaces (Mayhoub, 2014). 


\subsection{Light Transporter}

The lens system functions on the basis of the focal length of lenses and step by step light transmission. The space required for transmission of light is also obtained based on the focal length of lenses and their sizes. Efficiency decreases drastically under the influence of dust and air pollution (Bennett and Eijadi, 1980). Extensive expertise is required to secure optimum effectiveness of this system. Any displacement and vibration of the system considerably affect its performance and increase maintenance costs (Ayers and Carter, 1995).

However, the initial cost of operating a lens system is high due to the use of lenses. Each lens has a transmission coefficient of $92 \%$, but a number of lenses must be used in a series arrangement. According to researches, efficiency of this system after passage of light through 13 lenses is reported to be $28 \%$ (Hansen, 2006).

Prismatic light pipes (PLPs) are systems capable of transporting and diffusing light. Therefore, they are visually suitable and can easily combine natural and artificial lighting in one device. The efficiency of this system will be relatively high if rays of light are parallelized. To reduce the drop in light inside the pipes, the light entering the pipes must be at the acceptable angle (i.e. 27.6\% degrees). A flaw in system leads to light leakage from pipes (Ayers and Carter, 1995).

"Solid core" systems are considered light transportation components in which light is transported through internal reflection and surface reflection has no role in these systems (Hansen, 2006).

Internal reflection in solid core systems is highly efficient and diameter does not influence efficiency of systems. Therefore, this technology offers satisfactory physical flexibility in the building. Since the system carries light it can positively affect the interior design. Some of its problems are the limitation on supply of light at distances longer than $8 \mathrm{~m}$ and increasing the length decreases its efficiency. Mirrored light pipes (MLP) transport the diffuse sky light and direct sunlight using two different mechanisms (Aizenberg, 2000).

The diffuse light carried by light pipes consists of two parts: a direct part and a reflected part. The direct part decreases quickly from $100 \%$ to $1 \%$ after one meter, whereas the reflected part decreases by $29 \%$ per meter. Straight light pipes function better because any curvature reduces efficiency by $80 \%$. Pipe diameter is important when the azimuth angle of the light is taken into account. With an increase in the pipe length, its performance becomes more uniform over a day and a year. More importantly, horizontal light pipes must be short enough to be consistent with other secondary building systems installed under a roof.

Double light pipes (DLPs) were designed to develop the common light pipes. In this system, a transparent secondary pipe in addition to the primary pipe allows for illumination of the light transmission path. Therefore, a system that is capable of both transporting light into the space and distributing light in spaces crossed by light pipes will be suitable. Some of the advantages of this method are its potential for adaptive design and integration with spaces, and its aesthetical dimensions (Figure 5).
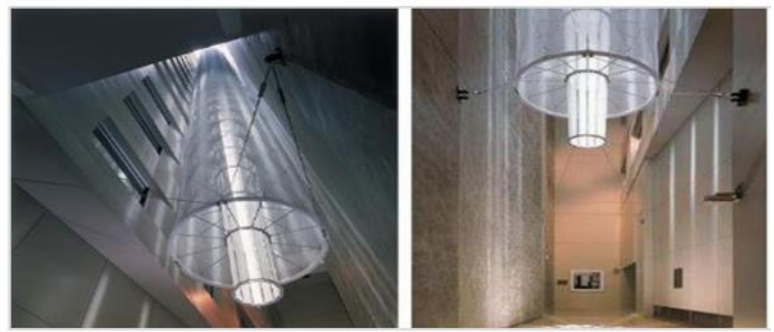

Figure 5. Double light pipes (Detail, 2004)

Since fiber-optics is capable of transporting visible light, they eliminate the adverse effects of ultraviolet rays and the heating effect of infrared light. These fibers offer high flexibility and physical adaptability in the post-installation phases (Hansen, 2006). Light ducts are supplied by the sky under cloudy weather conditions with minimum surrounding barriers. Efficiency of light ducts depends on factors such as the height to width ratio, length to width ratio, reflection coefficient of surfaces, and the light collection component. The physical flexibility of this system is low due to the limited size of ducts.

\section{3 Emitters}

1) Continuous Emitters:

Technologies such as prismatic pipe, double light pipe, luminescent pipe, fiber optics, and solid core systems fit into this category. Prismatic pipes lose $2 \%$ of their optical gain per $300 \mathrm{~mm}$, which results in local luminance in the beginning of the Emission phase. The light collected from the aforementioned system is a diffuse light with multidimensional shadows and sometimes causes glare (Ayers and Carter, 1995).

\section{2) Discrete Emitters:}

Some of the redirecting systems redirect the light into interior surfaces (the ceiling, walls, and floor). They can be grouped into the direct and diffuse reflection categories based on the quality of the reflected light (Faizi, et al, 2017). In the first category a window is used as the channel for Emission of light and the light can be distributed after it reflects in floor or ceiling. In redirecting systems two types of flat and concave mirrors are used for light emission. The flat and concave mirrors increase optical gain 11 and 15 times, respectively. Investigations also suggest that in the Emission phase this system transports a larger portion of light wavelengths and the emitted light will be highly similar to natural light.

Experiments have reflected the weakness of this system in the light Emission phase. The glare caused by the secondary mirror affects the interior visual quality. Moreover, the visual interference of the secondary mirror with the window view is another issue with this system (Kim and Kim, 2010).

Texture, colour and reflection coefficient of the floor and furniture will considerably influence system efficiency. The initial and secondary costs of this system are extremely low, and from the technical point of view it offers an acceptable level of maintenance and ease of installation. 
In the second category, several technologies have been introduced for distribution of diffuse light over the ceiling. Two of the most common technologies of this kind are light cones and laser cut panels. Research results showed that laser cut panels produce a more uniform light distribution than light cones whereas the light cones cause fewer glares (Hansen and Edmonds, 2003).

Since the light is reflected in the surfaces in a diffuse form, glare is prevented. The weakness of this system is the necessity of existence of parallel light rays which required complicated technologies.
In this step, the conceptual model is created as a new framework for finding integration component of IDS in buildings. They classified into four major categories: lighting performance, utilization, building compatibility, and social area (Table 6).

\subsection{Lighting Performance}

Lighting performance of IDS is the part of collected light that is transported into the interior space (Wang, et al, 2009).

\section{INTEGRATION ISSUE IN UTILIZATION OFIDS}

Table 6. The adaptation components of new daylighting strategies with light wells and buildings

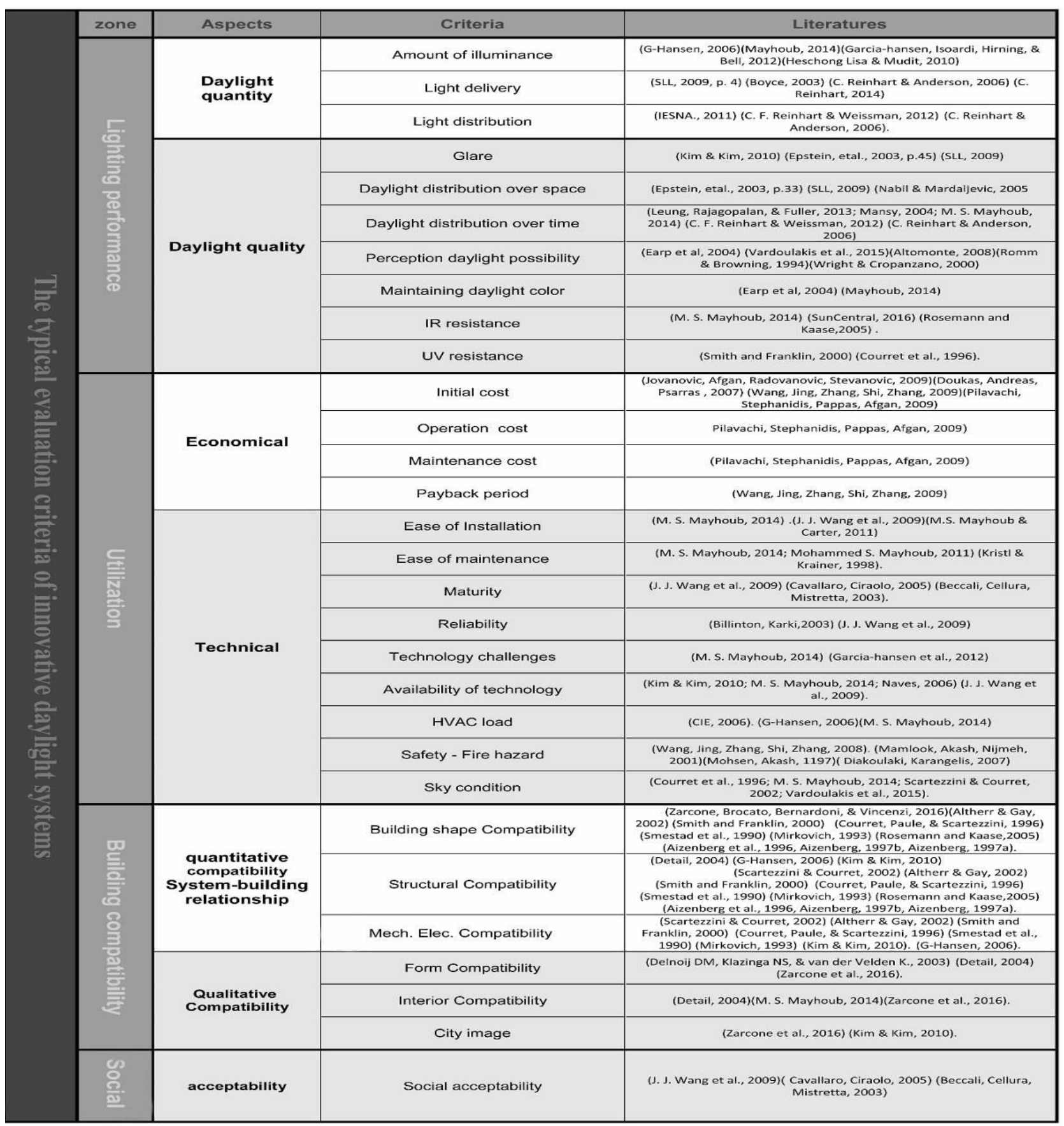


1) Daylight Quantity:

In IDS, light quantity is assessed using the following three criteria: amount of collected light, amount of directed light, and amount of light emitted. Each of these systems yields a different level of efficiency depending on the component technology (Reinhart, 2014).

\section{2) Daylight Quality:}

- Glare: It is a criterion determining the light contrast created by the system in the light Emission phase. Glare varies by Emission technology (Kim and Kim, 2010).

- Daylight distribution over the interior space: This criterion reflects uniformity of the light distributed in the space. Lighting uniformity not only ensures that light reaches all parts but also prevents glare due to the lack of "excessively bright spots" (SLL, 2009). In this regard, one of the new criteria for assessment of light in space is the "useful daylight luminance". This criterion not only allows for assessment of light quantity, but also assesses uniformity and geometrical distribution of light (Nabil and Mardaljevic, 2005).

- Daylight distribution over time: It is a criterion that indicates system effectiveness at different solar angles. The system that emits a more uniform light with lower fluctuations from the sunrise to the sunset is considered to have acceptable performance (Mayhoub, 2014). One of the criteria for assessment of light in the space is "Daylight Autonomy" which assesses hourly light distribution based on a specified intensity over a year (Reinhart and Weissman, 2012).

- Perception daylight possibility: It is one of the criteria influencing quality of light and acceptance of the reflected light as the natural light (Altomonte, 2008).

- Maintaining daylight colour: The wavelength of light changes in the transmission process and different colours of sunlight are diffused in the interior space depending on the technology in use. IR resistance: It reflects control over infrared ray and thermal load received from sunlight (Mayhoub, 2014).

- Ultraviolet ray resistance: It is prioritized depending on technologies used in systems and the possibility of attaching screening layers (Courret, et al, 1996)

\subsection{Utilization}

1) Economic Dimension:

- Initial cost or investment cost includes all of the costs of constructing and transporting the product (Gašparini, et al, 2014). There is a direct relationship between efficiency and construction cost (Jovanovic, et al, 2009).

- Operation cost: It includes all of the fees, government energy incentives and costs of system operating (Pilavachi, et al, 2009).

- Maintenance cost: It includes the costs of cleaning, overhauling, and replacing parts, which differs by system type (static-dynamic) (Mayhoub and Carter, 2011).

- Payback period: The payback period is the period required for the return of initial investment. As the payback period becomes shorter the cost-effectiveness of the system increases (Mayhoub, 2011). Service life: It is a criterion that reflects the period during which the system functions without performance errors (Wang, et al, 2009).
2) Technical Dimension:

- Ease of installation: The system is classified into the useroriented and expert-oriented groups depending on the expertise required for its installation and the installation process must be merged with the design process. Ease of maintenance: It is significantly related to the technological complexity (Mayhoub, 2014).

- Technical maturity: It is a technical assessment criterion, which reflects development of the system on the regional and global levels. In terms of technical maturity, tools are classified into four categories: "a) technologies only tested in laboratories; b) technologies that are manufactured as prototypes; c) technologies that are on the road to development; d) proven technologies that are close to elimination of theoretical limitations as for efficiency" (Wang, et al, 2009).

- Reliability: It reflects a system's ability to access the goals of design (Billinton and Karki, 2003).

- Technological challenges: Technologies are classified into the simple and complicate categories depending on the active/passive type of system and the level of light concentration (Mayhoub, 2014).

- Availability: Availability of manufacturing technologies and possibility of manufacture of parts sets the scene for the development of a system and its technical maturity (Naves, 2006).

- HVAC load: It is criterion which defined by the thermal load transferred by light ducts.

- Safety against fire hazard: The most important threat posed by lighting systems to buildings is fire because of the high light concentration and increased intensity of luminance (Wang, et al, 2009)

- Sky condition: It is a criterion that reflects effectiveness of a system under any sky condition (Vardoulakis, et al, 2015)

\subsection{Building Compatibility}

3) Structural (physical) Compatibility:

- Building shape compatibility: It is a criterion reflecting the physical relationship and compliance of systems with the building which can be varies according to the mechanism of different systems. Given the physical interference of systems for collecting, transporting, and Emission, this physical interference can be assessed in relation to the required space and dimensions (Zastrow and Wittwer, 1986).

- Structural compatibility: It reflects the relationship of the static and dynamic mechanisms of systems with the structure of buildings and the need for a secondary structure to allow for adaptation of systems to the building (Rosemann and Kaase, 2005).

- Mechanical and Electrical Compatibility: It is a criterion reflecting the amount of interference with mechanical installations. Since some systems utilize light and ventilation ducts simultaneously ventilation does not function properly. In some systems, transmission shaft creates unwanted thermal load and causes limitations (Hansen, 2006).

\section{4) Qualitative Compatibility}

Another aspect of the (IDS) and buildings interaction is the qualitative compatibility and systems can fit into the "building element" to "accessory" depending on the compatibility level. 
- Form compatibility: It is a criterion that shows the visual effect of a system on the building form. Attempts made by designers to consider aesthetical dimensions and visual rules in selecting tools that suit buildings, reflects the significance of physical consistency with buildings (Delnoij, et al, 2003).

- Interior space compatibility: It reflects the visual effect of a system on the interior space. Light emitters affect the visual quality of the interior space and cause challenges for architects (Mayhoub, 2014).

- City scape compatibility: It is a criterion that reflects the visual effect of a system on the cityscape. The effect of collectors on the city scape changes the skyline and the roof view, which are significant in the urban scale (Kim and Kim, 2010).

\subsection{Social Area}

5) Social acceptability:

Public attitude toward a technology considering the mental assumptions. Social acceptability drives society towards acceptance of a technology based on several criteria such as health and costs (Beccali, et al, 2003).

\section{CONCLUSION}

Current review paper has been developed based on four steps in order to finding challenges for improve the performance of "light well" as one of the conventional means of daylight penetration in deep plan buildings. Results of each step reveal the next step of research.

Results of the first step indicated that light well improvement methods in phase one and two (which have been designed since 1986 on the basis of the "Cartwright Sizing" rule) are under the influence of numerous physical limitations on the path towards improvement of light well performance, and this goal will not be attained based on the common light well index in urban contexts. On the other hand, results of analysis of light well improvement methods indicated that concerning phase three (utilization of IDS), which is based on the ability to realize the potentials of light wells for transmission of light, no fundamental research was conducted on the relationships between architecture (light wells) and innovative strategies. This gap drives the research toward the second step to clarify the challenges to utilization of innovative daylighting technologies.

Results of the second step revealed that studies conducted on daylight guiding technologies are classified into the following four categories: method of estimating system efficiency; improving system performance; presenting a decision-making model; and compatibility of the system with physical conditions. Very few studies have been carried out on the fourth group, but in this area the interaction of innovative daylighting technologies and different dimensions of building architecture is more significant. Seemingly, challenges faced by architects and policy makers in selecting a suitable system will be overcome in this section. In this regard, analysis of reviews in the interaction of daylight systems and buildings shows that, there are several parameters other than "light Performance assessment of system". These parameters influence the choice of suitable system for building. Lack of concern for internal and external parameters will result in non-compliance system. Hence, the next step is defined in the process of analysing IDS and discovering related components.

Results of the third step of the present research led to the development of a coherent framework for new daylight transmission systems that is capable of examining and discovering the important components. Accordingly, daylight guiding systems were classified by functions of their components (i.e. differences in collecting, transporting, and distributing light).

Results of step four led to development of a conceptual model recommended as the model consisting of components influencing compatibility of systems with buildings. This conceptual model is a new structure for understanding interactions of innovative daylight guiding systems with buildings. In steps two and three it was indicated that in spite of estimates of lighting efficiency of systems other components are involved in the interaction between systems and buildings and in selection of a system matching the building, and selection of a system based on lighting efficiency estimates will not yield satisfactory results. Therefore, based on the research conducted in step three, components affecting performance of systems were classified into 4 major scopes: lighting performance (effectiveness), utilization, building compatibility, and social area. Each of these groups can be measured with the corresponding criteria from different dimensions.

Based on the results of this research, the value and role of each component in selection of a suitable system will be studied in future researches, which will be conducted on experimental research and the necessity of extracting components influencing the design of IDS improvement in proportion to native and regional conditions. This can determine the optimum combination of tools and physical components of buildings for increasing efficiency of lighting of adjacent spaces and estimating the efficiency of these systems. Future research, which will be focused on creation of a proper combination of collection, transportation and Emission for light wells, will be of value for development and application purposes and will lead to maximum utilization of the daylight in buildings and develop of light penetration into the core of buildings.

\section{REFERENCES}

Ayers, M. J., and D. J. Carter., 1995. Remote source electric light systems: A review. Lighting Research and Technology, 27(1), pp. 1-15.

Aizenberg, J. B. 2000. From the history of hollow light guides and their efficient applications. Light \& Engineering, 8, pp.35-48.

Aizenberg, J. B., Buob, W., Signer, R., Korobko, A. A. and Pyatigorsky, V. M. 1996. Solar and artificial lighting of a School building with hollow light guide system. Svetotekhnika, 4, pp.41-54.

Bennett, D., and Eijadi, D., 1980. Solar optics: Projecting Light into Buildings. AIA Journal, 69, PP.72-74. 
Billinton, R., and Karki, R., 2003. Reliability/cost implications of utilizing photovoltaics in small isolated power systems. Reliability Engineering \& System Safety, 79, pp.11-6.

Beccali, M., Cellura, M., Mistretta, M., 2003. DecisionApplication of the electret method at regional level for the diffusion making in energy planning of renewable energy technology. Renewable Energy 2003, 28, pp. 2063-87.

Courret, G., Paule, B., Scartezzini, J. L., 1996. Anidolic zenithal openings: Daylighting and shading. Lighting Research and Technology, 28, pp.11-17.

Delnoij, D.M., Klazinga, N.S., van der Velden, K., 2003. Building integrated. European Journal of Public Health.

Earp, A. A., Smith, G. B., Franklin, J., Swift, P., 2004. Optimization of a three - color luminescent solar concentrator daylighting system. Solar Energy Materials and Solar Cells, 84, pp. 411-426.

Faizi, M., Mehdizadeh Seraj, F., Gholipour Gashniani, M., 2016. Review of the innovative strategies to improve daylight penetration in building. Journal of Fundamental and Applied Sciences, 8(3S), pp. 1428-1447.

Faizi, M., Gholipour Gashniani, M., Maleki, M., 2017. Investigating the potential of the innovative strategies in dense city. 3rd_ILDC Iran lighting design conference, Tehran, Iran.

Freewan, A. a Y., Gharaibeh, A. a., Jamhawi, M. M., 2014. Improving daylight performance of light wells in residential buildings, Nourishing compact sustainable urban form. Sustainable Cities and Society, 13, pp. 32-40.

Gašparini, K., Nasser, A., Sladić, S., 2014. The fault tolerant led power converter design for more efficient and durable lighting. Engineering Review, 34 (3), pp.189-195.

Jovanovic, M., Afgan N., Radovanovic, P., Stevanovic, V., 2009. Sustainable development of the Belgrade energy system. Energy, 34, pp.532-9.

Kim, J. T., and Kim, G., 2010. Overview and new developments in optical daylighting systems for building a healthy indoor environment. Building and Environment, 45(2), pp. 256-269.

Mayhoub, M. S., 2014. Innovative daylighting systems' challenges: A critical study. Energy and Buildings, 80, pp.394-405.

Mayhoub, M. S., and Carter, D. J., 2011. The costs and benefits of using daylight guidance to light office buildings. Building and Environment, 46(3), pp. 698-710.

Pilavachi, PA., Stephanidis, SD., Pappas, VA., Afgan, NH, 2009. Multi-criteria evaluation of hydrogen and natural gas fuelled power plant technologies. Applied Thermal Engineering, 29, pp. 2228-34.
Reinhart, C. F., and Weissman, D. a., 2012. The daylight area. Building and Env, 50, pp. 155-164.

Rosemann, A., and Kaase, H. (2005). Light pipe applications for daylighting systems. Solar Energy, 78, pp. 772-80.

Rosemann, A., Mossman, M., Whitehead, L., 2008. Development of a cost-effective solar illumination system to bring natural light into the building core. Solar Energy, 82(4), pp. $302-310$

Vardoulakis, S., Dimitr Oulopoulou, C., Thornes, J., Lai, K.M., Taylor, J., Myers, I., Wilkinson, P., 2015. Impact of climate change on the domestic indoor environment and associated health risks in the UK. Environment International, 85 , pp.299-313.

Wang, J. J., Jing, Y. Y., Zhang, C. F., Zhao, J. H., 2009. Review on multi-criteria decision analysis aid in sustainable energy decision-making. Renewable and Sustainable Energy Reviews, 13(9), pp.2263-2278.

Altomonte, S., 2008. Daylight for Energy Savings and Psycho-Physiological Well-Being in Sustainable Built Environments, pp. 3-16.

Hansen, V. R., 2006. Innovative daylighting systems for deep-plan commercial buildings. Faculty of Built Environment and Engineering, (Queensland University).

Hansen, G., and Edmonds, I., 2003. Natural illumination of deep-plan office buildings: light pipe strategies, (June), pp. 14-19.

Mayhoub, M. S., 2011. Hybrid lighting systems. Thesis University of Liverpool, (July).

Naves, E., 2006. The evaluation of daylight guide systems and their impact on building design.

Reinhart, C., 2014. Daylighting handbook Volume I: fundamentals, designing with the Sun., (Place of publication and publisher not identified.).

SLL, 2009. The SLL Lighting Handbook. Construction. 222 Balham High Road, London SW12 9BS.

Zastrow, A., and Wittwer, V., 1986. Daylight with mirror light pipes and with fluorescent planar concentrators. SPIE 692 - Materials and optics for solar energy conversion and advanced lighting technology, pp. 227-34.

Advanced building ltd, 2010. http://www Advancedbuilding.com, (view at May. 2010).

Himawari, www.himawari-net.co (view at June. 2013).

Parans, 2013.www.parans.com (view at May. 2013).

Sundolier, 2013. www.Sundolier.com (view at Oct. 2013). 